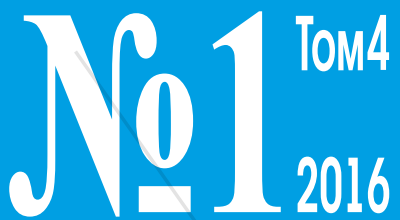

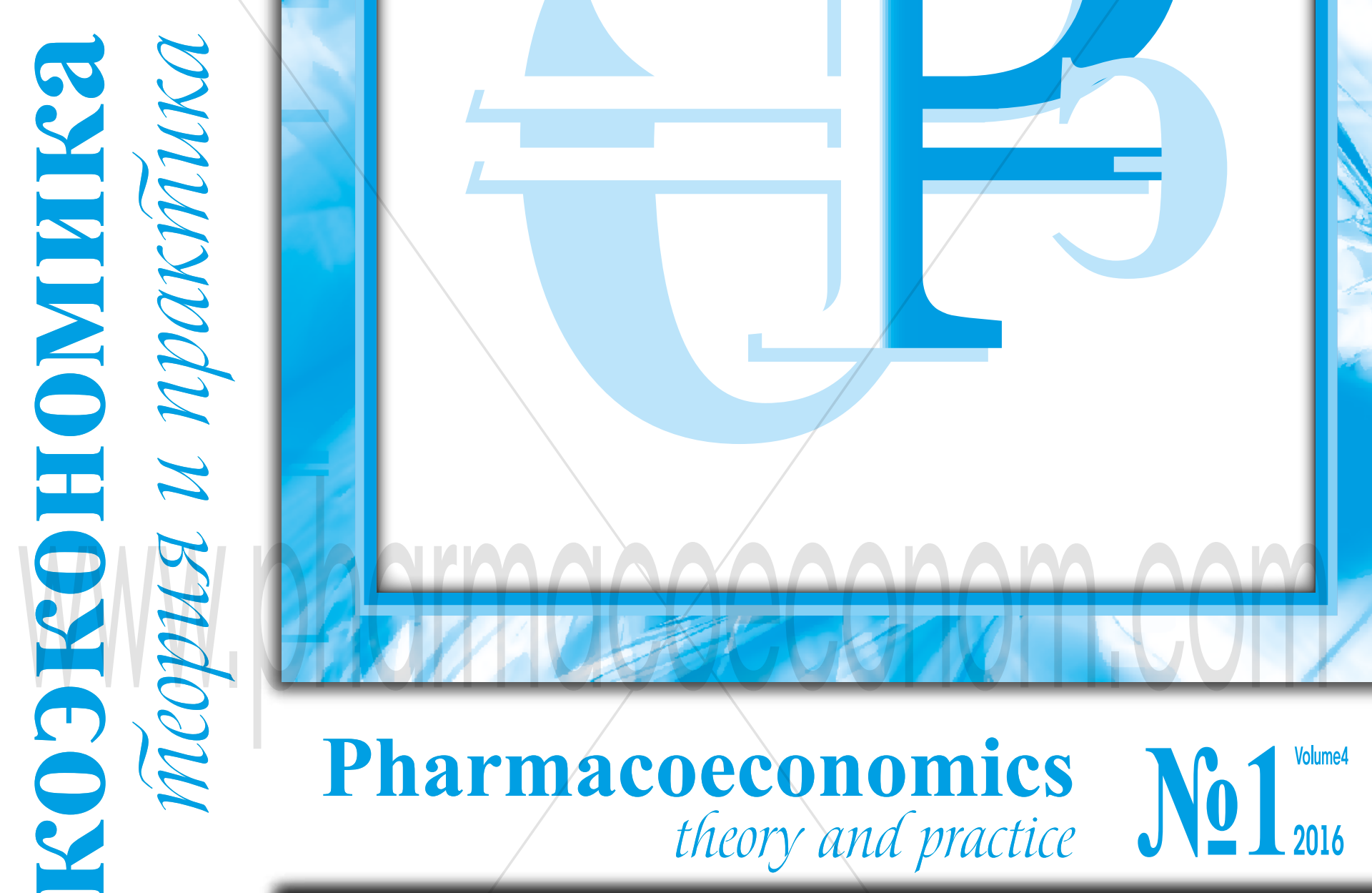

$\square$ МЕТОДОЛОГИЧЕСКИЕ ОСНОВЫ ФАРМАКОЭКОНОМИЧЕСКОГО МОДЕЛИРОВАНИЯ

$\square$ РЕЗУЛЬТАТЫ РОССИЙСКИХ ФАРМАКОЭКОНОМИЧЕСКИХ ИССЛЕДОВАНИЙ

口 МАТЕРИАЛЫ Х НАЦИОНАЛЬНОГО КОНГРЕССА С МЕЖДУНАРОДНЫМ УЧАСТИЕМ «РАЗВИТИЕ ФАРМАКОЭКОНОМИКИ И ФАРМАКОЭПИДЕМИОЛОГИИ В РОССИЙСКОЙ ФЕДЕРАЦИИ» 4-5 апреля 2016 г., г. Нижний Новгород 


\title{
АНАЛИЗ ЗАТРАТ НА ПРОТИВОДИАБЕТИЧЕСКИЕ ЛЕКАРСТВЕННЫЕ ПРЕПАРАТЫ ПРИ ОКАЗАНИИ МЕДИЦИНСКОЙ ПОМОЩИ ПРИКРЕПЛЕННЫМ К ВОЕННО-МЕДИЦИНСКИМ ОРГАНИЗАЦИЯМ ПАЦИЕНТАМ С САХАРНЫМ ДИАБЕТОМ В АМБУЛАТОРНЫХ УСЛОВИЯХ COST ANALYSIS OF ANTIDIABETIC DRUGS IN THE HEALTH CARE DELIVERY ATTACHED TO THE MILITARY MEDICAL ORGANIZATIONS DIABETIC PATIENTS IN OUTPATIENT SETTINGS
}

\author{
Щерба М.П., Мирошниченко Ю.В. \\ Scherba M.P., Miroshnichenko Yu.V. \\ Военно-медицинкая академия им. С.М. Кирова, г. Санкт-Петербург \\ S.M. Kirov Military Medical Academy, Saint-Petersburg
}

Ключевые слова: Военно-медицинские организации, детализированный анализ "стоимости болезни», сахарный диабет, стандарт оказания медицинской помощи, средняя стоимость курса лечения, формуляр лекарственных средств.

Цель исследования: провести анализ затрат на противодиабетические лекарственные препараты (ЛП) при оказании медицинской помощи прикрепленным к военно-медицинским организациям (BMO) пациентам с сахарным диабетом (СД) в амбулаторных условиях

Материалы и методы: контент-анализ; методы рационального фармацевтического менеджмента и фармакоэкономического анализа (детализированный анализ «стоимости болезни»).

Результаты: Приказом Минздравсоцразвития Российской Федерации (РФ) от 11.12.2007 г. № 748 «0б утверждении стандарта медицинской помощи больным с инсулиннезависимым СД» и приказом Минздрава России от 28.12.2012 г. № 1581н «Об утверждении стандарта первичной медико-санитарной помощи при инсулиннезависимом СД» утверждень 2 стандарта медицинской помощи по лечению пациентов с СД 2 типа в амбулаторных условиях. При этом медицинскими организациями и подразделениями Вооруженных Сил (ВС) РФ используется 5-е издание Формуляра лекарственных средств медицинской службы (далее - Формуляр), который носит ограничительный характер и способствует рациональному сокращению номенклатуры используемых ЛП. Обязательное использование в медицинской практике стандартов и Формуляра предопределяет необходимость их применения при расчете и прогнозировании потребности в фринансовых ресурсах для лекарственного обеспечения (ЛО) военнослужащих и пенсионеров Министерства обороны РФ, страдающих СД. Нами были произведены расчеты средней стоимости курса лечения пациентов с СД 2 типа (ССКЛ) по международным непатентованным наименованиям (МHH); по группам препаратов согласно анатомо-терапевтическо-химической (ATX); по группам препаратов в соответствии с фрармакотерапевтической классификацией. Частота назначений (ЧН) учитывалась по данным федеральных стандартов. Полученные данные о ССКЛ позволили выявить существенные различия как между двумя сравниваемыми стандартами, так и Формуляром. Так, затраты по фрармакотерапевтической группе (ФТГ) «Инсулины и средства для лечения СД», рассчитанные на основе стандартов 2012 г. и 2007 г., Формуляра, составили 7236,2 руб. (без учета ЧН - 23651,51 руб.), 3995,2 руб. (без учета ЧН - 12843,8 руб.), 6734,8 руб. (без учета ЧН - 18277,19 руб.) в год на одного пациента соответственно. Следует отметить, что количество противодиабетических ЛП, включенных в стандарт 2012 г., превышает количество представленных в стандарте 2007 г. и Формуляре в 1,7 и 1,8 раз соответственно. При этом лишь 55\% ЛП рассматриваемой ФТГ, представленных в стандарте 2012 г. включены в действующий перечень жизненно необходимых и важнейших ЛП (ЖНВЛП). Это может свидетельствовать 0 недостаточно рациональном расходовании ресурсов в данной ситуации. Кроме того, представленные в рассматриваемых нормативных документах ЛП недостаточно соответствует современным рекомендациям по фрармакотерапии пациентов с СД, представленным в 7-м издании алгоритмов специализированной медицинской помощи больным СД. Если же производить расчет учитывая только препараты с зарегистрированной ценой, оказалось, что затраты на терапию противодиабетическими ЛП могут быть сокращены более чем в 2 раза (по стандарту 2012 г.), на 20\% (по Формуляру), на 2,5\% (по стандарту 2007 г.). В результате проведенного анализа были также выявлены значительные различия в затратах на фармакотерапию в каждой из проанализированных ATX-групп. В зависимости от препарата затраты на фрармакотерапию одного пациента в год могли варьировать в несопоставимых диапазонах. Например, в группе «Производные сульфоонилмочевины» стоимость годового курса лечения без учета ЧН препаратом «Глибенкламид» составила 2681,8 руб., «Гликвидон» - 11388,7 руб., «Гликлазид» $-8140,6$ руб. Следует отметить, что среди ЛП, входящих в перечень ЖНВЛП стоимостной диапазон варьировал в допустимых пределах.

Заключение: одним из инструментов планирования затрат на лекарственную помощь в ВС РФ должен быть Формуляр и стандарты медицинской помощи. Однако на практике их применение затруднено в связи с существенными разночтениями в содержании, не позволяющими гармонизировать ЛО гражданских и прикрепленных к ВМ0 пациентов. Кроме того, механизмы своевременной актуализации фрармакотерапии в соответствии с пересматриваемым перечнем ЖНВЛП и с утвержденными рекомендациями специалистов недостаточно эффрективны в настоящее время. 